\title{
Dermatoses Following Nepal Earthquake 2015
}

\section{Karn D}

Department of Dermatology

Dhulikhel Hospital, Kathmandu University Hospital

Dhulikhel, Kavre, Nepal

Nepal experienced the biggest earthquake for 80 years on $25^{\text {th }}$ April 2015. It measured 7.9 Richter scale and was centered on two districts, Gorkha and Sindhupalchowk of central Nepal. There were hundreds of aftershocks that continued for more than 2 months. It killed nearly 10,000 people and thousands of people were left homeless. The acute effects of the earthquake were leaned largely to the orthopedics department. However every medical fraternity had to face effects following it. An attempt has been made to summarize the acute effects on the skin of the survivors. Cutaneous disease was seen to be a frequent cause of morbidity among homeless survivors.

Wounds following trauma and its infections were the direct effects of earthquake. However the indirect cutaneous effects were more predominant than the direct effects. The evident indirect effects were mainly because of two reasons; due to destruction of physical infrastructure and because of psycho-emotional factors. Most of the sufferers had damaged homes which were unsafe to stay. So, they stayed outside in a tent because of the fear. Lack of food, shelter, water supply and problems because of rain were the major issues for the survivors. Infections and infestations including pyoderma, chicken pox, measles, fungal infections (superficial cutaneous infections including tinea versicolor) and scabies were seen because of overcrowding and lack of hygiene. Insect bite reactions with secondary pyoderma and photodermatoses were a major concern among many. Nevertheless pigmentary cosmetic disorders as melasma and freckles also flared up.

As a result of multifactorial process including psycho-emotional stress, trauma and direct ultraviolet exposure diseases such as atopic dermatitis, lupus erythematosus, psoriasis, vitiligo, neurotic pruritus and immunobullous disorders flared up. Disorder of hair as telogen effluvium and nail disorders as nail splitting, Beau's lines were also evident.

Papular urticaria following insect bite reaction was reported to be the commonest dermatoses (24\%) following an earthquake in Sichuan, China in $2008 .{ }^{1}$ Ambient temperature at that period for insects $\left(35-38^{\circ} \mathrm{C}\right)$ was related for the high incidence. Similarly parasitic infestations were reported to be common after Duzce earthquake, Turkey in $1999 .{ }^{2}$ Hence the early need of insect repellents, preferably in cream form has been felt following these incidents. Disaster training and preparedness including provision of first aid kit in every house has been emphasized. The prevalence of cutaneous diseases has also been evaluated in a cohort of homeless people. ${ }^{3}$ The major problems were attributed to malnutrition, exposure to hazardous environment, psychiatric disease, physical injuries, and limited access to health care.

In the last decade (2004-2013), over 6500 disasters happened in the world that has caused 1,059,072 deaths and billions of US dollars damage. ${ }^{4}$ Most of the natural disasters cannot be anticipated and occurs unexpectedly causing its maximum damage. Although the presenting manifestations may be diverse the major reasons behind post disaster health problems can be attributed to lack of physical infrastructure, stress and lack of sanitation. Hence early restoration of physical structures and measures to prevent epidemics and flare up of existing diseases are the foremost steps to be taken following a natural disaster.

Nepal is an earthquake prone zone. Earthquake of 2015 was a great learning experience for every Nepalese citizen. Despite various challenges, we learned to address issues involving overcrowding, shelter, lack of sanitation, waste management, supply of food/water, access to health care and communicable disease surveillance. Any magnitude of earthquake may happen in one's lifetime. Hence disaster preparedness involving earthquake resistant homes, buildings, trained citizens and health care workers are our future necessities. 


\section{REFERENCES}

1. Renshan S, Tangyou Z, Chunxue L, Hong C, Jinjin W. Dermatoses reports in Wenchuan districts of Sichuan province after 5.12 earthquake. Int J Med and Med Sci. 2009; 1(10):462-63.

2. Oztas MO, Onder M, Oztas P, Atahan C. Early skin problems after Düzce earthquake. Int J Dermatol. 2000; 39(12):952-53.

3. Stratigos AJ, Stern R, Gonzalez E, Johnson RA, O'Connell J, Dover JS. Prevalence of skin disease in a cohort of shelter-based homeless men. J Am AcadDErmatol. 1999;41:197-202.

4. International Federation of Red Cross and Red Crescent Societies. World disasters report, 2014. Available from: https://www.ifrc.org/world-disastersreport-2014/data. Accessed: July 72015. 